\title{
MicroRNA-30b protects myocardial cell function in patients with acute myocardial ischemia by targeting plasminogen activator inhibitor-1
}

\author{
BIN LI, JIE HU and XINGPENG CHEN \\ Department of Cardiac Surgery, Luoyang Central Hospital Affiliated to Zhengzhou University, \\ Luoyang, Henan 471009, P.R. China
}

Received October 14, 2017; Accepted January 18, 2018

DOI: $10.3892 /$ etm.2018.6039

\begin{abstract}
The aim of the present study was to determine the expression of plasminogen activator inhibitor-1 (PAI-1) and microRNA (miR)-30b in the blood of patients with acute myocardial ischemia (AMI) and in the blood and myocardial tissue of mice with AMI. In addition, the present study aimed to identify the mechanism of action of miR-30b in AMI. A total of 36 patients with AMI were included in the present study and 28 healthy subjects were included as a control. Peripheral blood was collected from all subjects. For animal experiments, mice in the AMI group received an intraperitoneal injection of pituitrin $(20 \mathrm{U} / \mathrm{kg})$, whereas mice in the negative control group received an intraperitoneal injection of the same volume of saline. Blood and myocardial tissue was collected from all mice for analysis. Reverse transcription-quantitative polymerase chain reaction was performed to determine the expression of PAI-1 mRNA and miR-30b in the serum and myocardial tissue. An enzyme-linked immunosorbent assay was performed to measure the expression of PAI-1 protein in the serum of humans and mice, whereas western blotting was performed to determine the expression of PAI-1 protein in mouse myocardial tissue. Catalase, glutathione peroxidase and superoxide dismutase activity was measured using an automatic biochemical analyzer. A dual luciferase assay was performed to identify the interactions between PAI-1 mRNA and miR-30b. The results indicated that patients with AMI have higher PAI-1 levels and lower miR-30b expression in the peripheral blood compared with healthy subjects. AMI damaged the myocardium tissue of mice and reduced catalase, glutathione peroxidase and superoxide dismutase activity.
\end{abstract}

Correspondence to: Dr Xingpeng Chen, Department of Cardiac Surgery, Luoyang Central Hospital Affiliated to Zhengzhou University, 288 Zhongzhou Road, Luoyang, Henan 471009, P.R. China

E-mail: xingpeng852@163.com

Key words: acute myocardial ischemia, plasminogen activator inhibitor-1, microRNA-30b
Mice that have undergone AMI exhibit increased PAI-1 levels but decreased miR-30b expression in the peripheral blood and myocardial tissues. It was also demonstrated that miR-30b is able to bind to the 3'-untranslated region of PAI-1 mRNA to regulate its expression. The present study demonstrates that patients with AMI exhibit decreased miR-30b expression and elevated PAI-1 expression in the peripheral blood. miR-30b may therefore inhibit the damage to myocardial cells that occurs following AMI and protect myocardial cell function by targeting PAI-1 expression.

\section{Introduction}

Myocardial ischemia (MI) is one of the most severe cardiovascular diseases, which poses a serious threat to human health (1) and is expected to become the most common cause of mortality worldwide by 2030 (2). At present, 7.3 million people succumb to ischemic heart disease each year globally, which accounts for $12.8 \%$ of all mortalities due to disease (3). Acute myocardial ischemia (AMI) is usually caused by coronary atherosclerotic heart disease (4). A number of risk factors induce the formation of atherosclerosis in the coronary arteries, including aging, high blood pressure, high cholesterol, diabetes, smoking, lack of physical activity and obesity $(5,6)$. This leads to narrowing or obstruction of the lumen, which in turn, causes MI, hypoxia and myocardial cell death, which is responsible for cardiac dysfunction (4). A number of studies have demonstrated that changes in coagulation and fibrinolysis stimulate the formation and development of atherosclerotic and thrombotic diseases. Coronary heart disease, particularly acute coronary syndrome, is closely associated with an increase in blood coagulation activity and a decrease in fibrinolytic activity $(7,8)$. The treatment for MI primarily includes lifestyle changes, drug treatment and surgery. Lifestyle changes include maintaining a healthy diet and mental health. Drugs may be used to reduce blood lipid content, inhibit platelet aggregation and control angina pectoris, while surgical measures include coronary artery bypass grafting, atrioventricular valvuloplasty or replacement and ventricular reduction (9).

Plasminogen activator inhibitor-1 (PAI-1) is a serine protease inhibitor that inactivates tissue ( $\mathrm{t}$ )- and urokinase-PA, inhibits intravascular fibrinolysis, causes changes in blood 
rheology and aggravates ischemic injury (10). In addition, PAI-1 is associated with the abnormal activation of platelets $(11,12)$ and is a risk factor for the onset and development of ischemic heart and brain diseases $(13,14)$.

Previous studies performing miRNA expression profiling have demonstrated that microRNA (miRNA) molecules serve important roles in the pathology of MI $(15,16)$ and miRNAs regulate the expression of various genes by direct targeting mRNA $(17,18)$. miRNAs that exist in the blood are also reliable biological markers associated with a number of diseases, including MI $(19,20)$. It has been reported that miR-30b regulates the proliferation and apoptosis of gastric cancer cells by targeting PAI-1 (21). However, to the best of our knowledge, it remains unknown whether miR-30b regulates PAI-1 in MI. Therefore, in the present study, the expression of miR-30b and PAI-1 in the blood of patients with AMI and in the blood and myocardial tissue of mice with AMI was determined. The current study also aimed to understand the mechanism by which AMI occurs.

\section{Materials and methods}

Patients. A total of 36 patients aged $65.6 \pm 11.8$ years old (range, 46-82 years) with AMI receiving treatment at the Luoyang Central Hospital Affiliated to Zhengzhou University (Luoyang, China) between August 2012 and January 2017 were included in the present study. Out of the 36 patients, there were 26 males and 10 females. A total of 21 patients received immediate treatment by percutaneous coronary intervention (PCI) and 15 patients received selective PCI at another time. A control group consisting of 28 healthy subjects (16 males and 12 females) aged $61.15 \pm 8.6$ years old (range, 50-70 years old) were included in the current study. Peripheral blood was collected from patients with AMI within $6 \mathrm{~h}$ of MI onset and healthy subjects on the day of physical examination. Serum was isolated from peripheral blood by centrifugation at $4^{\circ} \mathrm{C}$ at $1,000 \mathrm{x} \mathrm{g}$ for $10 \mathrm{~min}$. The present study was approved by the Ethics Committee of Zhengzhou University (Henan, China) and written informed consent was obtained from all participants or their families.

Animals. A total of 60 male BALB/C mice (4 weeks old; weighing 18-22 g) were purchased from Chongqing Tengxin Biotechnology Co., Ltd. (http://www.cqtx123.com/; Chongqing, China) with a numbered certificate [SCXK(Yu) 2015-0012]. For 1 week prior to the experiments, mice had ad libitum access to food and water. The animals were maintained at $24 \pm 2^{\circ} \mathrm{C}$ and $55 \pm 5 \%$ humidity in cages with a $12 \mathrm{~h}$ light/dark cycle. The Reduction, Replacement and Refinement animal welfare principle (22) was followed during the experiments. All mice were evenly divided into two groups (each, $n=30$ ): A control group and an AMI model group.

Following 1 week adaptive feeding, all mice received intraperitoneal injection of urethane $(1,300 \mathrm{mg} / \mathrm{kg})$ to induce anesthesia. Mice were kept in a supine position and needle electrodes were inserted into the subcutaneous layers of the limbs. An animal twelve-lead electrocardiograph (ECG-1350P; Nihon Kohden, Tokyo, Japan) was used to record a lead II electrocardiogram of normal mice $(10 \mathrm{~mm}$ on the chart represented standard voltage $1 \mathrm{mV}$; chart speed,
$50 \mathrm{ram} / \mathrm{s}$ ). Mice in the AMI group were intraperitoneally injected with pituitrin (20 U/kg; Shanghai Pharma, Shanghai, China) to construct AMI mouse model. Mice in the control group were intraperitoneally injected with an equal volume of saline. After $30 \mathrm{~min}$, the lead II electrocardiogram of mice in the control and AMI groups was recorded again. Changes in J point voltage on the electrocardiogram prior to and following ischemia were observed and the $\mathbf{J}$ point shift $(\mathrm{mV})$ of each group was recorded using the PR segment as a baseline. A total of 30 min following construction of AMI mouse model, blood was collected from the eyes of mice under anesthetic in the control and AMI groups. The blood was then centrifuged at $1,200 \mathrm{x} \mathrm{g}$ for $15 \mathrm{~min}$ at $4^{\circ} \mathrm{C}$ to obtain serum. Subsequently, mice were sacrificed by decapitation, myocardial tissues were collected and stored in liquid nitrogen. All animal experiments were conducted according to the ethical guidelines of Zhengzhou University (Henan, China).

Reverse transcription-quantitative polymerase chain reaction (RT-qPCR). Myocardial tissues (100 mg) were ground using liquid nitrogen and mixed with $1 \mathrm{ml}$ TRIzol (10606ES60; Shanghai Yeasen Biotechnology, Co., Shanghai, China) for lysis. Serum samples $(100 \mu \mathrm{l})$ were directly mixed with $1 \mathrm{ml}$ TRIzol for lysis. Total RNA was then extracted using the phenol chloroform method as previously described (23). The concentration and quality of RNA was assessed using ultraviolet spectrophotometry (Nanodrop ND2000, Thermo Scientific, Inc., Wilmington, DE, USA). Reverse transcription of mRNA was performed using TIANScript II cDNA First Strand Synthesis kit (Tiangen Biotech Co., Ltd., Beijing, China) and reverse transcription of miRNA was performed using an miRcute miRNA cDNA First Strand Synthesis kit (Tiangen Biotech, Co., Ltd.). cDNA was stored at $-20^{\circ} \mathrm{C}$. A SuperReal PreMix (SYBR Green) RT-qPCR kit (Tiangen Biotech, Co., Ltd.) was used to detect the expression of PAI-1 mRNA. The sequences of the primers used to detect human PAI-1 were: PAI-1, forward, 5'-AATGACTGGGTGAAGACA CACACA-3' and reverse, 5'-TTCCACTGGCCGTTGAAG TAGA-3'; $\beta$-actin, forward, 5'-TGGCACCCAGCACAATGA A-3' and reverse, 5'-CTAAGTCATAGTCCGCCTAGAAGC A-3'. The sequences of the primers used to detect mouse PAI-1 were as follows: PAI-1, forward, 5'-AGGGCTTCATGCCCC ACTTCTTCA-3' and reverse, 5'-AGTAGAGGGCATTCA CCAGCACCA-3'; GAPDH, forward, 5'-CAAGGTCATCCA TGACAACTTTG-3' and reverse, 5'-GTCCACCACCCTGTT GCTGTAG-3'. The qPCR reaction system $(20 \mu \mathrm{l})$ to detect PAI-1 consisted of $10 \mu \mathrm{l}$ RT-qPCR-Mix, $0.5 \mu \mathrm{l}$ upstream

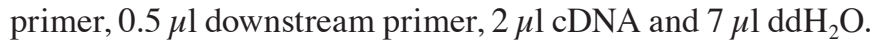
The qPCR conditions were as follows: Initial denaturation at $95^{\circ} \mathrm{C}$ for $2 \mathrm{~min}$; 40 cycles of denaturation at $95^{\circ} \mathrm{C}$ for $25 \mathrm{sec}$, annealing at $55^{\circ} \mathrm{C}$ for $30 \mathrm{sec}$ and elongation at $72^{\circ} \mathrm{C}$ for $30 \mathrm{sec}$; final extension at $72^{\circ} \mathrm{C}$ for $30 \mathrm{sec}$. qPCR was performed using an iQ5 Real-Time PCR system (Bio-Rad Laboratories, Inc., Hercules, CA, USA). The $2^{-\Delta \Delta C q}$ method (24) was used to calculate the relative expression of human PAI-1 mRNA against $\beta$-actin and the relative expression of mouse PAI-1 mRNA against GAPDH. Each sample was tested in triplicate.

The expression of miR-30b was determined using the miRcute miRNA RT-PCR kit (Tiangen Biotech, Co., Ltd), using U6 as internal reference. The sequences of the primers 
used to detect human miR-30b were: Forward, 5'-CGCGCT GTAAACATCCTACAC-3' and reverse, 5'-GTGCAGGGT CCGAGGT-3'; U6, forward, 5'-GCTTCGGCAGCACAT ATACTAAAAT-3' and reverse, 5'-CGCTTCACGAATTTG CGTGTCAT-3'. The PCR reaction system $(20 \mu \mathrm{l})$ for human miR-30b determination was composed of $10 \mu \mathrm{l}$ RT-qPCR-Mix, $0.5 \mu \mathrm{l}$ upstream primer, $0.5 \mu \mathrm{l}$ downstream primer, $2 \mu \mathrm{l} \mathrm{cDNA}$ and $7 \mu \mathrm{ddH}_{2} \mathrm{O}$. PCR conditions for human miR-30b determination were: Initial denaturation at $95^{\circ} \mathrm{C}$ for $5 \mathrm{~min}$; 40 cycles of denaturation $95^{\circ} \mathrm{C}$ for $10 \mathrm{sec}$, annealing at $60^{\circ} \mathrm{C}$ for $20 \mathrm{sec}$ and elongation at $72^{\circ} \mathrm{C}$ for $10 \mathrm{sec}$; final extension at $72^{\circ} \mathrm{C}$ for $5 \mathrm{~min}$. qPCR was performed using the iQ5 Real-Time PCR system.

The sequences used to detect mouse miR-30b were, forward, 5'-GCGCCTGTAAACATCCTACAC-3' and reverse, 5'-GTGCAGGGTCCGAGGT-3'; U6, forward, 5'-GCTTCG GCAGCACATATACTAA-3' and reverse, 5'-AACGCTTCA CGAATTTGCGT-3'. The PCR reaction system $(25 \mu \mathrm{l})$ for mouse miR-30b determination was composed of $12.5 \mu \mathrm{lSYBR}$ Premix EXTaq ${ }^{\mathrm{TM}}$ (Takara Biotechnology Co., Ltd., Dalian, China), $0.5 \mu \mathrm{l}$ upstream primer, $0.5 \mu \mathrm{l}$ downstream primer, $1 \mu \mathrm{l} \mathrm{cDNA}$ and $10.5 \mu \mathrm{l} \mathrm{ddH}_{2} \mathrm{O}$. qPCR conditions for mouse miR-30b determination were: Initial denaturation at $95^{\circ} \mathrm{C}$ for $30 \mathrm{sec} ; 45$ cycles of denaturation at $95^{\circ} \mathrm{C}$ denaturation for $5 \mathrm{sec}$ and annealing at $60^{\circ} \mathrm{C}$ for $30 \mathrm{sec}$; elongation at $72^{\circ} \mathrm{C}$ for $45 \mathrm{sec}$; final extension at $72^{\circ} \mathrm{C}$ for $5 \mathrm{~min}$. qPCR was performed using an iQ5 Real-Time PCR system. The $2^{-\Delta \Delta C q}$ method was used to calculate the relative expression of miR-30b against U6. Each sample was tested in triplicate.

Enzyme-linked immunosorbent assay (ELISA). Sera were examined using human and mouse PAI-1 ELISA kits [cat. nos. ab108891 (human) and ab197752 (mouse); Abcam, Cambridge, UK] according to the manufacturer's protocol. In microplates, standards $(50 \mu \mathrm{l})$, samples $(10 \mu \mathrm{l}$ sample liquid and $40 \mu \mathrm{l}$ diluent) and blank were set into predefined wells. In the wells for standards and samples, horseradish peroxidase-labelled conjugates $(100 \mu \mathrm{l})$ were added before sealing the plates for incubation at $37^{\circ} \mathrm{C}$ for $1 \mathrm{~h}$. The plates were washed 5 times and then substrates $\mathrm{A}(50 \mu \mathrm{l})$ and $\mathrm{B}(50 \mu \mathrm{l})$ were added to each well. Following incubation at $37^{\circ} \mathrm{C}$ for $15 \mathrm{~min}$, stop solution $(50 \mu \mathrm{l})$ was added to each well and the absorbance of each well was measured at $450 \mathrm{~nm}$.

Western blotting. Precooled radioimmunoprecipitation assay lysis buffer $(600 \mu \mathrm{l} ; 50 \mathrm{mM}$ Tris-base, $1 \mathrm{mM}$ EDTA, $150 \mathrm{mM} \mathrm{NaCl}, 0.1 \%$ sodium dodecyl sulfate, $1 \%$ Triton $\mathrm{X}-100$, $1 \%$ sodium deoxycholate; Beyotime Institute of Biotechnology, Haimen, China) was used to lyse the samples. Following lysis for $50 \mathrm{~min}$ on ice, the mixture was centrifuged at $18,000 \mathrm{x} \mathrm{g}$ and $4^{\circ} \mathrm{C}$ for $5 \mathrm{~min}$. Protein concentration of the supernatant was determined using a bicinchoninic acid protein concentration determination kit [RTP7102; Real-Times (Beijing) Biotechnology Co., Ltd., Beijing, China]. Protein samples $(20 \mu \mathrm{g})$ were then mixed with SDS loading buffer prior to denaturation in a boiling water bath for $5 \mathrm{~min}$. The samples were then subjected to $10 \%$ SDS-PAGE. Resolved proteins were transferred to polyvinylidene difluoride membranes on ice $(100 \mathrm{~V}, 2 \mathrm{~h})$ and blocked with $5 \%$ skimmed milk at room temperature for $1 \mathrm{~h}$. Subsequently, membranes were incubated with rabbit anti-mouse PAI-1 polyclonal (1:1,000; cat. no. ab7205; Abcam) and rabbit anti-mouse $\beta$-actin (1:5,000; cat. no. ab8227; Abcam) primary antibodies at $4^{\circ} \mathrm{C}$ overnight. Following three washes with phosphate-buffered saline with Tween 20 (15 min/wash), membranes were incubated with goat anti-rabbit horseradish peroxidase-conjugated secondary antibody (1:3,000; cat. no. ab6721; Abcam) for $1 \mathrm{~h}$ at room temperature prior to three washes with phosphate-buffered saline with Tween 20 (15 min/wash). The membrane was developed using an enhanced chemiluminescence detection kit (Abcam). Image lab v3.0 software (Bio-Rad Laboratories, Inc.) was used to acquire and analyze imaging signals. The relative content of PAI-1 protein was expressed as the ratio of PAI- $1 / \beta$-actin.

Bioinformatics. Bioinformatics prediction is a powerful tool to study the function of miRNAs. To determine the regulatory mechanism of PAI-1, miRanda (http://www.microrna.org/ microrna/home.do), TargetScan (http://www.targetscan.org), PiTa (http://genie.weizmann.ac.il/pubs/mir07/mir07_data.html), RNAhybrid (http://bibiserv.techfak.uni-bielefeld.de/rnahybrid/) and PICTA (http://pictar.mdc-berlin.de/) were used to predict the miRNA molecules that may regulate PAI-1. The results indicated that miR-30b was potentially able to regulate PAI-1 (Fig. 1).

Automatic biochemical analysis. The activities of catalase (CAT; cat. no. A007-1-1), glutathione peroxidase (GSH-Px; cat. no. A005) and superoxide dismutase (SOD; cat. no. A001-2-1) were determined using the appropriate kits (Nanjing Jiancheng Bioengineering Institute, Nanjing, China) following the manufacturer's protocol. Following the addition of all reagents, absorbance was measured continuously over a 5 min period. The activities of CAT, GSH-Px and SOD were determined by the increase rate of average absorbance per minute in the linear segment. The results were automatically calculated using an AU5800 automatic biochemical analyzer (Beckman Coulter, Inc., Brea, CA, USA).

Dual luciferase reporter assay. The results of bioinformatics were used to chemically synthesize the wild-type (WT) and mutant seed regions of miR-30b in the 3'-untranslated region (UTR) of PAI-1 gene in vitro. SpeI and HindIII restriction sites were added and UTRs were then cloned into pMIR-REPORT luciferase reporter plasmids (Thermo Fisher Scientific, Inc., Waltham, MA, USA). Plasmids $(0.8 \mu \mathrm{g})$ containing WT or mutant 3'-UTR DNA sequences were co-transfected with agomiR-30b (100 nM; Sangon Biotech, Co., Ltd., Shanghai, China) into 293T cells using Lipofectamine ${ }^{\circledR} 2000$ (Invitrogen; Thermo Fisher Scientific, Inc.). Following 24 h cultivation, activity was assessed using a dual luciferase reporter assay kit (Promega Corporation, Madison, WI, USA), following the manufacturer's protocol and fluorescence intensity was measured using a GloMax 20/20 luminometer (Promega Corporation). Using Renilla luciferase fluorescence activity as an internal reference, the fluorescence values of each group of cells were measured.

Statistical analysis. The results were analyzed using SPSS 18.0 statistical software (SPSS, Inc., Chicago, IL, USA). All data are expressed as the mean \pm standard deviations. 


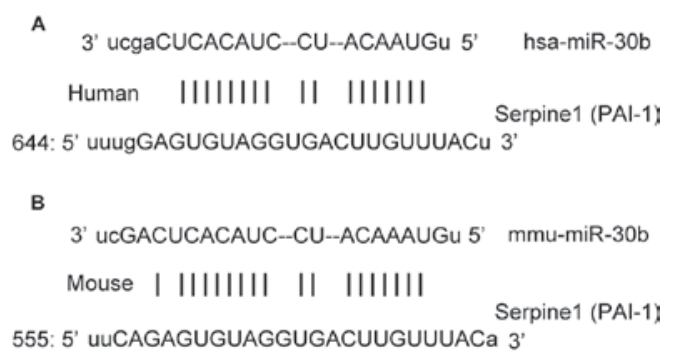

Figure 1. Direct interaction between miRNA-30b and PAI-1 in (A) humans and (B) mice. Bioinformatic prediction is a useful method of studying miRNA function. To determine the regulatory mechanism of PAI-1, miRanda (http://www.microrna.org/microrna/home.do), TargetScan (http://www. targetscan.org), PiTa (http://genie.weizmann.ac.il/pubs/mir07/mir07_data .html), RNAhybrid (http://bibiserv.techfak.uni-bielefeld.de/rnahybrid/) and PICTA (http://pictar.mdc-berlin.de/) were used to predict the miRNA molecules that might regulate PAI-1. It was indicated that miR-30b regulates PAI-1. UTR, untranslated region; PAI-1, plasminogen activator inhibitor-1; miR, microRNA.

Data were tested for normality. Multigroup measurement data were analyzed using one-way analysis of variance. In cases of homogeneity of variance, the Least Significant Difference and Student-Newman-Keuls methods were used as a post-hoc test; in cases of heterogeneity of variance, Tamhane's T2 or Dunnett's T3 method was used. $\mathrm{P}<0.05$ was determined to indicate a statistically significant difference.

\section{Results}

Patients with AMI exhibit elevated PAI-1 expression in the peripheral blood. To measure the expression of PAI-1 mRNA and protein in the serum of patients with AMI compared with healthy controls, RT-qPCR and ELISA were performed. The results demonstrated that levels of PAI-1 mRNA and protein in the serum of patients with AMI were significantly higher than in healthy controls $(\mathrm{P}<0.01$ and $\mathrm{P}<0.05$; Fig. $2 \mathrm{~A}$ and $\mathrm{B}$, respectively), confirming that patients with AMI exhibit elevated PAI-1 expression in the peripheral blood.

Patients with AMI exhibit reduced miR-30b levels in the peripheral blood. To measure the expression of miR-30b in the peripheral blood of patients and healthy controls, RT-qPCR was performed. The results demonstrated that the expression of miR-30b in the serum of patients with AMI was significantly decreased compared with the control group ( $\mathrm{P}<0.05$; Fig. 3 ), indicating that patients AMI exhibit decreased miR-30b expression.

The J point voltage in electrocardiogram is enhanced and the activities of SOD, CAT and GSH-Px are decreased in mice with AMI. To determine changes in the associated physiological and biochemical indexes in the mouse model of AMI, electrocardiography and an automatic biochemical analyzer were used. The results indicated that the $\mathrm{J}$ point voltage in mice with AMI was significantly higher than mice in the negative control group $(\mathrm{P}<0.05$; Table I). In addition, the activity of SOD, CAT and GSH-Px in the peripheral blood of mice with AMI was significantly increased compared with mice in the negative control group
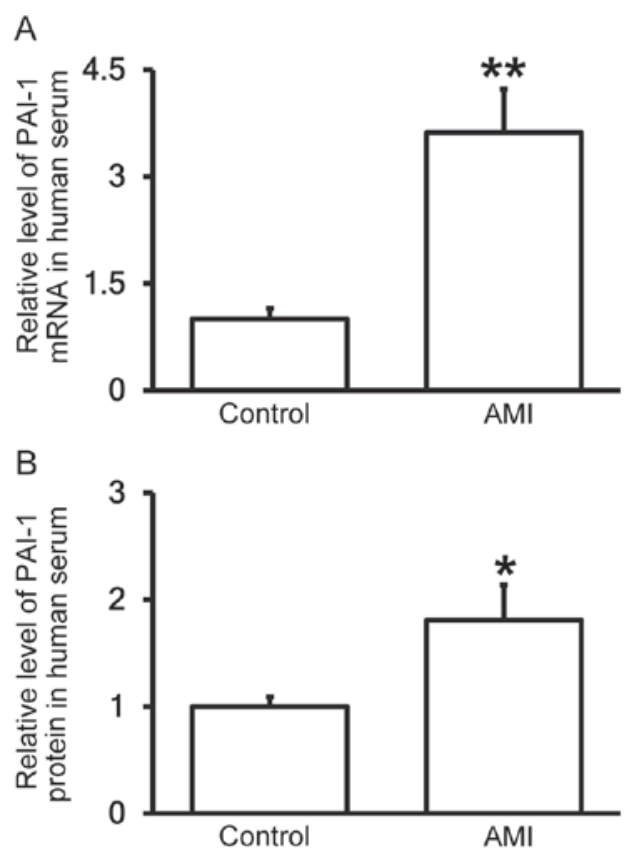

Figure 2. Expression of PAI-1 (A) mRNA and (B) protein in the serum of patients with AMI compared with healthy subjects. Reverse transcription-quantitative polymerase chain reaction was performed to measure the expression of PAI-1 mRNA, whereas an enzyme-linked immunosorbent assay was used to determine the expression of PAI-1 protein in the serum. Data are expressed as the mean \pm standard deviation. ${ }^{*} \mathrm{P}<0.05$ and ${ }^{* *} \mathrm{P}<0.01$ vs. the control. AMI, acute myocardial infarction; PAI-1, plasminogen activator inhibitor-1.

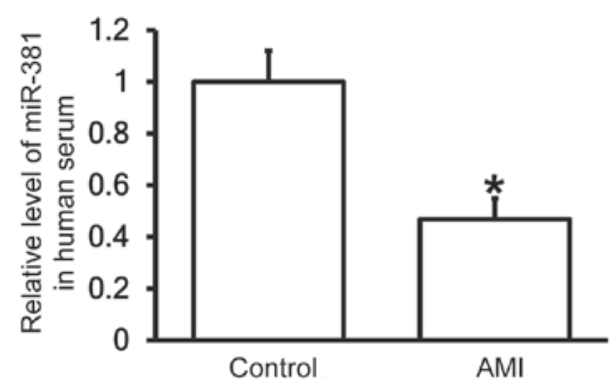

Figure 3. Expression of miR-30b in the serum of patients with AMI compared with those of healthy controls. Reverse transcription-quantitative polymerase chain reaction was used to measure the expression of miR-30b in the serum. Data are expressed as the mean \pm standard deviation. ${ }^{*} \mathrm{P}<0.05$ vs. the control. miR-30b, microRNA-30b; MI, myocardial infarction.

(all $\mathrm{P}<0.05$ ). These results indicate that AMI may enhance the $\mathrm{J}$ point voltage and decrease SOD, CAT and GSH-Px activity.

AMI model mice exhibit increased PAI-1 levels in the peripheral blood. To measure the expression of PAI-1 mRNA and protein in the serum of mice, RT-qPCR and ELISA were performed. The results demonstrated that levels of PAI-1 mRNA and protein in the serum of mice with AMI were significantly higher than in the negative control group (each $\mathrm{P}<0.05$; Fig. 4A and $\mathrm{B}$ ). These results suggest that PAI-1 levels are increased in the blood following AMI and are consistent with the results from patients with AMI. 
Table I. Changes in levels of physiological and biochemical indexes in the mouse model of AMI.

\begin{tabular}{lccccc}
\hline Groups & $\mathrm{N}$ & $\mathrm{J}$ point voltage $(\mathrm{mV})$ & $\mathrm{SOD}(\mathrm{mkat} / \mathrm{ml})$ & CAT $(\mathrm{mkat} / \mathrm{ml})$ & $\mathrm{GSH}-\mathrm{Px}(\mathrm{mkat} / \mathrm{ml})$ \\
\hline Negative control & 30 & $0.016 \pm 0.03$ & $3.96 \pm 0.53$ & $6.28 \pm 0.96$ & $0.31 \pm 0.85$ \\
AMI model & 30 & $0.25 \pm 0.15^{\mathrm{a}}$ & $2.16 \pm 0.56^{\mathrm{a}}$ & $3.18 \pm 0.63^{\mathrm{a}}$ & $0.15 \pm 0.61^{\mathrm{a}}$ \\
\hline
\end{tabular}

${ }^{\mathrm{a}} \mathrm{P}<0.05$ vs. negative control group. AMI, acute myocardial infarction; SOD, superoxide dismutase; CAT, catalase; GSH-Px, glutathione peroxidase.
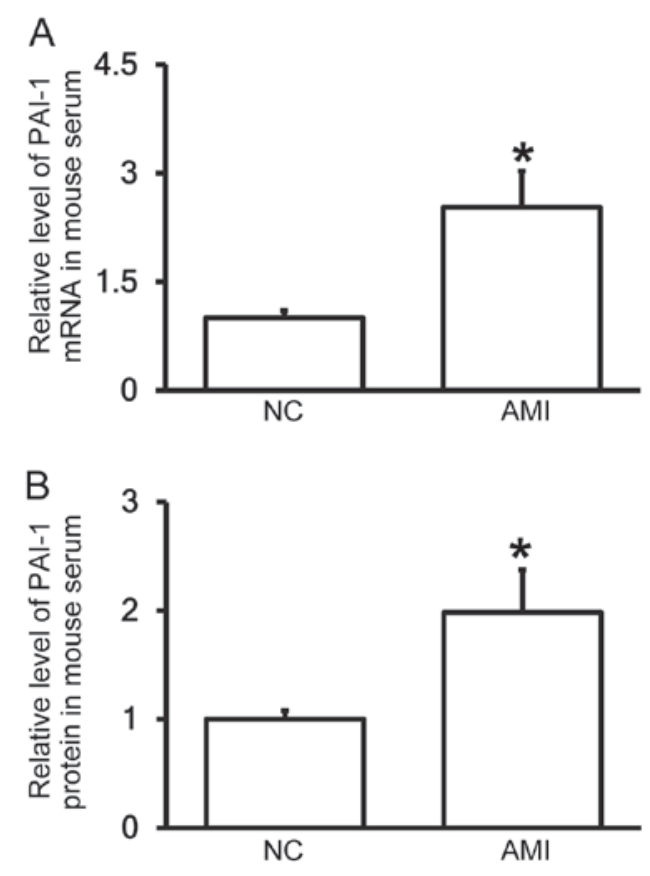

Figure 4. Expression of PAI-1 (A) mRNA and (B) protein in serum of mice with AMI compared with the NC. Reverse transcription-quantitative polymerase chain reaction was used to measure the expression of PAI-1 mRNA, whereas an enzyme-linked immunosorbent assay was used to determine the expression of PAI-1 protein in the serum. Data are expressed as the mean \pm standard deviation $(n=30)$. ${ }^{*} \mathrm{P}<0.05$ vs. the NC. $\mathrm{NC}$, negative control; AMI, acute myocardial infarction; PAI-1, plasminogen activator inhibitor-1.

Mice with AMI exhibit increased PAI-1 expression in myocardial tissue. To determine the levels of PAI-1 mRNA and protein in myocardial tissue, RT-qPCR and western blotting were performed. The results demonstrated that levels of PAI-1 mRNA and protein in the myocardial tissues of mice with AMI were significantly higher than those in the negative control group (each $\mathrm{P}<0.01$; Fig. $5 \mathrm{~A}$ and $\mathrm{B}$ ), indicating that mice with AMI exhibit increased PAI-1 expression.

Mice with AMI exhibit decreased miR-30b levels in the peripheral blood and myocardial tissues. To determine the expression of miR-30b in the peripheral blood and myocardial tissue of mice, RT-qPCR was conducted. The results demonstrated that the expression of miR-30b in the serum and myocardial tissues of mice with AMI was significantly reduced compared with the negative control group $(\mathrm{P}<0.05$ and $\mathrm{P}<0.01$; Fig. $6 \mathrm{~A}$ and $\mathrm{B}$, respectively), indicating that mice with AMI exhibit decreased miR-30b levels.
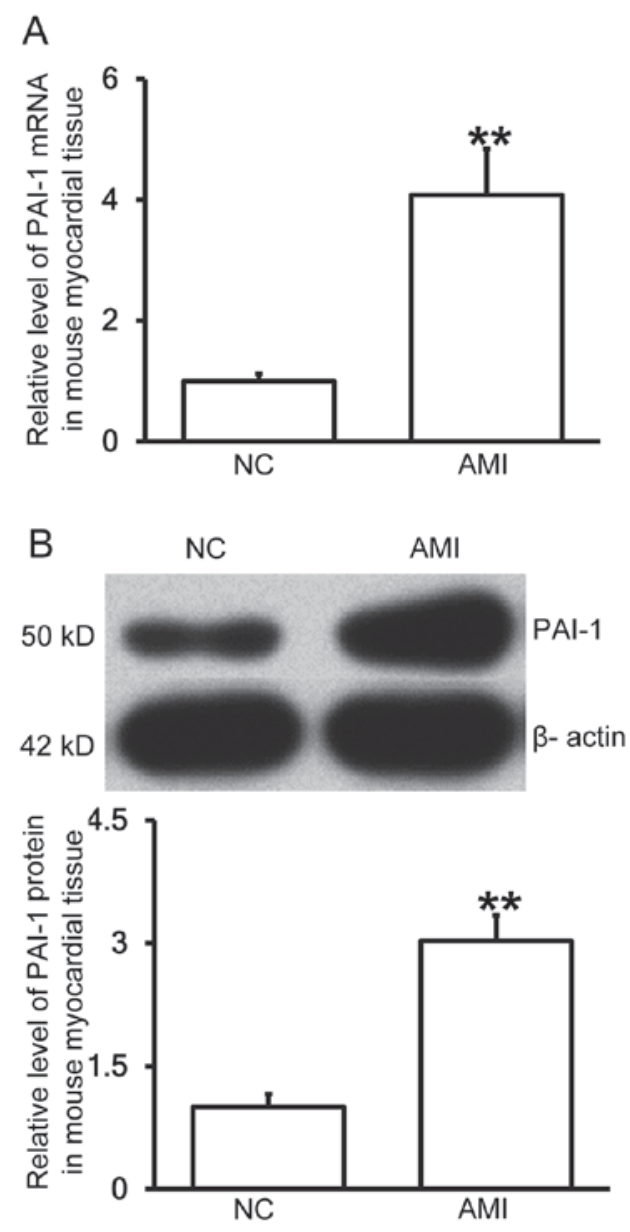

Figure 5. Expression of PAI-1 (A) mRNA and (B) protein in myocardial tissues from mice with AMI compared with the NC group. Reverse transcription-quantitative polymerase chain reaction was used to measure the expression of PAI-1 mRNA, whereas western blotting was used to determine the expression of PAI-1 protein. Data are expressed as the mean \pm standard deviation $(\mathrm{n}=30) .{ }^{* *} \mathrm{P}<0.01$ vs. NC. NC, negative control; AMI, acute myocardial infarction; PAI-1, plasminogen activator inhibitor-1.

miR-30b is able to bind to the 3'-UTR seeding region of PAI-1 mRNA to regulate its expression. To identify the interaction between miR-30b and the 3'-UTR of human PAI-1 mRNA, a dual luciferase reporter assay was performed. The fluorescence value of cells co-transfected with agomiR-30b and pMIR-REPORT-WT luciferase reporter plasmids was significantly lower than that of the negative control group $(\mathrm{P}<0.01$; Fig. 7). By contrast, the fluorescence value of cells co-transfected with agomiR-30b and pMIR-REPORT-mutant luciferase reporter plasmid did not differ significantly to that 

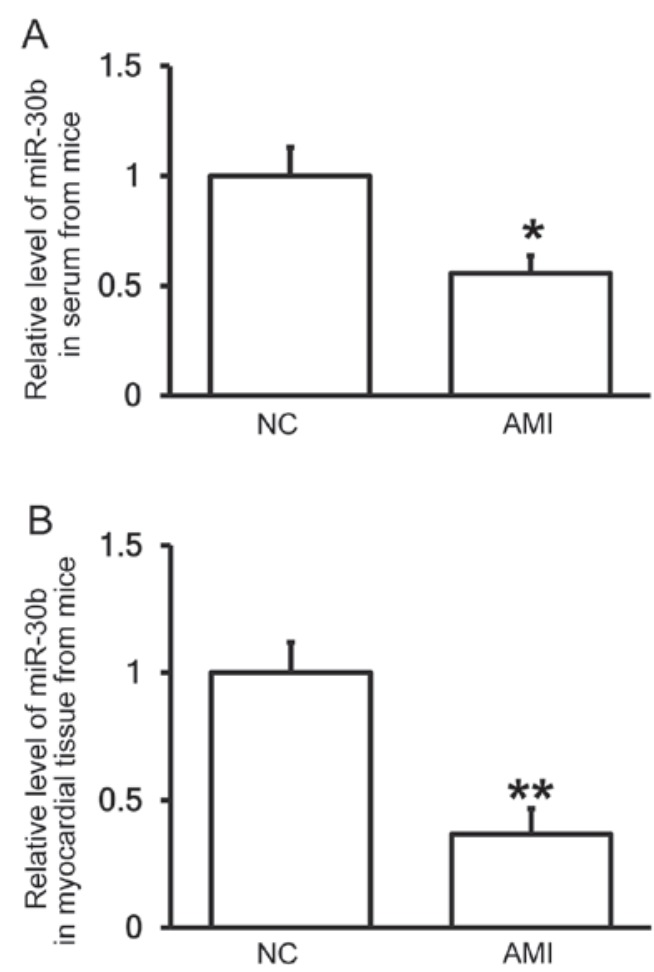

Figure 6. Expression of miR-30b in the (A) serum and (B) myocardial tissues from mice with AMI compared with the NC group. Reverse transcription-quantitative polymerase chain reaction was used to measure the expression of miR-30b in each group. Data are expressed as the mean \pm standard deviation $(n=30)$. ${ }^{*} \mathrm{P}<0.05$ and ${ }^{* *} \mathrm{P}<0.01$ vs. the NC. AMI, acute myocardial infarction; NC, negative control; miR-30b, microRNA-30b.

of the negative control group (Fig. 7). These results indicate that miR-30b is able to bind to the 3'-UTR seeding region of PAI-1 mRNA, thus regulating its expression.

\section{Discussion}

MI is a pathological condition in which blood perfusion of the heart is decreased, the oxygen supply to the heart is reduced and myocardium metabolism is deregulated (25). Due to the increased availability of high-energy, processed food and the adoption of more sedentary lifestyles (5), the prevalence of MI in China is increasing (26). MI is usually caused by vasculopathy and an insufficient blood supply to the heart $(27,28)$. Vasculopathy is associated with abnormal changes in blood coagulation and fibrinolysis and is a primary cause of thrombosis $(29,30)$. tPA and PAI-1 are important active substances in the fibrinolytic system and PAI-1 inhibits the action of tPA. It has been reported that PAI-1 and tPA are closely associated with ischemic cardiovascular disease $(31,32)$. PAI-1 is also closely associated with vascular disease and participates in the accumulation of extracellular matrix, as well as the proliferation and migration of smooth muscle cells. It also stimulates the binding of low-density lipoprotein to vascular smooth muscle cells $(33,34)$. PAI-1 deposits in the extracellular matrix facilitate the formation of atherosclerotic plaques, thicken the vascular basement membrane and stiffen the vascular walls, thus promoting the onset and development of vasculopathy and therefore atherosclerosis (35-37). PAI-1 is considered to

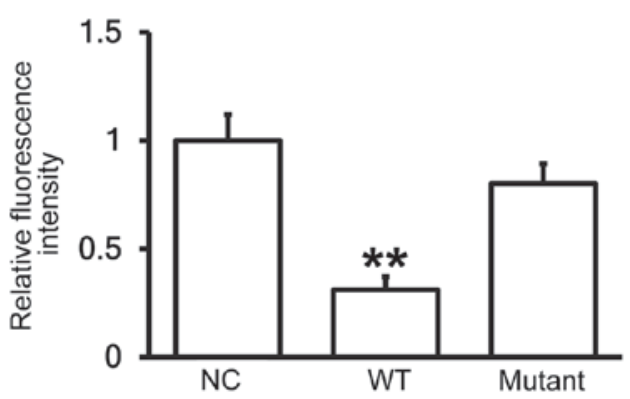

Figure 7. Identification of interaction between miR-30b and PAI-1 using a dual luciferase reporter assay. Renilla fluorescence activity was used as an internal reference. Data are expressed as the mean \pm standard deviation $(\mathrm{n}=30) .{ }^{* *} \mathrm{P}<0.01$ vs. the NC. miR-30b, microRNA-30b; PAI-1, plasminogen activator inhibitor-1; NC, negative control; WT, wild-type.

be closely associated with vascular disease (38); therefore, it is important to determine the regulatory mechanism of action of PAI-1.

The present study identified the relevant factors in AMI in the peripheral blood. Subsequently, an AMI mouse model was constructed using pituitrin. The animal model of MI induced by pituitrin has been widely used in the screening of anti-MI drugs $(39,40)$ and the progression of AMI and the pathological changes that occur in this particular mouse model are very similar to what occurs in patients with AMI. The results of the current study demonstrated that the expression of PAI-1 in the serum of patients with AMI is upregulated, indicating that abnormal changes in coagulation and fibrinolysis occur in such patients. The results of the electrocardiogram confirmed the successful construction of the AMI mouse model.

Maintaining the balance of free radicals in the blood is dependent on the activity of the free radical-scavenging enzymes SOD, CAT and GSH-Px (41-43). When tissues and cells are ischemic and anoxic, the function of the scavenging system is impaired, the activities of these enzymes decrease and they react with the proteins and nucleic acids in the cells. This causes a cascade of changes in cell structure and function that eventually damages myocardial cells (41-43). In the current study, upregulation of PAI-1 expression in the blood and myocardium of mice was also observed, further indicating that PAI-1 serves an important role in AMI.

miRNAs are posttranscriptional regulators. It has been reported that miRNAs participate in various cardiac physiological and pathological processes, including cardiac development, cardiac hypertrophy, heart failure and vascular proliferation (44). Wang et al (45) demonstrated that miR-142-3p protects against damage in the cardiomyocytes induced by hypoxia/reoxygenation by targeting the high mobility group box 1 gene. Singh et al (46) reported that miR-200c directly regulates the expression of dual specificity protein phosphatase 1, downregulates the activity of the mitogen-activated protein kinase signaling pathway and promotes cardiomyocyte hypertrophy. Based on the results of a study investigating the regulation of PAI-1 by miRNA (47), the present study used bioinformatics to identify the miRNA that regulates PAI-1 expression; the results indicated that miR-30b regulates PAI-1. Previous studies have demonstrated that miR-30b affects the 
proliferation and apoptosis of coronary artery endothelial cells via integrin subunit $\alpha 4$, phospholipase $\gamma 1$ (48), caspase 3 (49) and Bcl-2 (50). Furthermore, myocardial miR-30b serves anti-apoptotic and protective roles during the pathological process of heart ischemia reperfusion $(51,52)$. These studies suggest that miR-30b may be closely associated with the onset and development of heart disease in humans. The results of the present study indicate that the expression of miR-30b in the blood of patients with AMI is significantly decreased. Furthermore, the expression of PAI-1 is abnormally high in the blood of patients with AMI. This suggests that the downregulation of miR-30b may stimulate the upregulation of PAI-1. The current study obtained similar results regarding miR-30b and PAI-1 expression in the blood and myocardial tissues of mice with AMI, indicating that miR-30b negatively regulates PAI-1 in other species as well as humans. Furthermore, the results of the dual luciferase reporter assay indicated that miR-30b regulates the expression of PAI-1 by directly targeting the 3'-UTR of PAI-1 mRNA.

In conclusion, the results of the present study demonstrate that the expression of miR-30b is reduced and the expression of PAI-1 is increased following AMI and that these changes alter the expression of t-PA and u-PA proteins. Therefore, miR-30b serves an important role in AMI and may be developed as a potential biomarker in the diagnosis and treatment of AMI

\section{Acknowledgements}

Not applicable.

\section{Funding}

No funding was received.

\section{Availability of data and materials}

The analyzed data sets generated during the study are available from the corresponding author on reasonable request.

\section{Author contributions}

BL conceived and designed the study, performed experiments and collected and analyzed the data. JH collected and analyzed data. XC conceived and designed the study, drafted and revised the manuscript and gave final approval of version to be published. The final version of the manuscript has been read and approved by all authors.

\section{Ethical approval and consent to participate}

All procedures performed in the current study were approved by the Ethics Committee of Zhengzhou University. Written informed consent was obtained from all patients or their families.

\section{Consent for publication}

Written informed consent was obtained from all participants or their families for the publication of their data.

\section{Competing interests}

The authors declare that they have no competing interests.

\section{References}

1. Nabel EG and Braunwald E: A tale of coronary artery disease and myocardial infarction. N Engl J Med 366: 54-63, 2012.

2. Mathers CD and Loncar D: Projections of global mortality and burden of disease from 2002 to 2030. PLoS Med 3: e442, 2006.

3. Zhou H, Ma Q, Zhu P, Ren J, Reiter RJ and Chen Y: Protective role of melatonin in cardiac ischemia-reperfusion injury: From pathogenesis to targeted therapy. J Pineal Res 64: e12471, 2018.

4. Fuke Y, Yasutsune T and Sakamoto M: Aortic valve replacement after coronary artery bypass grafting with the in situ right gastroepiploic artery to the occluded right coronary artery using a temporary vein graft for cardioplegia. Surg Case Rep 3: 56, 2017.

5. Orth-Gomér K, Deter HC, Grün AS, Herrmann-Lingen C, Albus C, Bosbach A, Ladwig KH, Ronel J, Söllner W, de Zwaan M, et al: Socioeconomic factors in coronary artery disease-results from the SPIRR-CAD study. J Psychosom Res 105: 125-131, 2018.

6. Kundi H, Kiziltunc E, Korkmaz A, Cicek G, Ornek E and Ileri M: A novel risk scoring system to predict cardiovascular death in patients with acute myocardial infarction: CHA2DS2-VASc-CF score. Clin Appl Thromb Hemost 24: 273-278, 2018.

7. Folsom AR, Aleksic N, Park E, Salomaa V, Juneja H and Wu KK: Prospective study of fibrinolytic factors and incident coronary heart disease: The atherosclerosis risk in communities (ARIC) study. Arterioscler Thromb Vasc Biol 21: 611-617, 2001.

8. Rosenfeld ME: An overview of the evolution of the atherosclerotic plaque: From fatty streak to plaque rupture and thrombosis. Z Kardiol 89 (Suppl 7): S2-S6, 2000.

9. Moran AE, Forouzanfar MH, Roth GA, Mensah GA, Ezzati M, Murray CJ and Naghavi M: Temporal trends in ischemic heart disease mortality in 21 world regions, 1980 to 2010: The global burden of disease 2010 study. Circulation 129: 1483-1492, 2014.

10. Hua Y, Xi G, Keep RF, Wu J, Jiang Y and Hoff JT: Plasminogen activator inhibitor-1 induction after experimental intracerebral hemorrhage. J Cereb Blood Flow Metab 22: 55-61, 2002.

11. Pieters M, Barnard SA, Loots DT and Rijken DC: The effects of residual platelets in plasma on plasminogen activator inhibitor-1 and plasminogen activator inhibitor-1-related assays. PloS One 12: e0171271, 2017.

12. Deng ZY, Shan WG, Wang SF, Hu MM and Chen Y: Effects of astaxanthin on blood coagulation, fibrinolysis and platelet aggregation in hyperlipidemic rats. Pharm Biol 55: 663-672, 2017.

13. Eitzman DT, Westrick RJ, Xu Z, Tyson J and Ginsburg D: Plasminogen activator inhibitor-1 deficiency protects against atherosclerosis progression in the mouse carotid artery. Blood 96: 4212-4215, 2000.

14. Kohler HP and Grant PJ: Plasminogen-activator inhibitor type 1 and coronary artery disease. N Engl J Med 342: 1792-1801, 2000.

15. Chang TY, Tsai WC, Huang TS, Su SH, Chang CY, Ma HY, Wu CH, Yang CY, Lin CH, Huang PH, et al: Dysregulation of endothelial colony-forming cell function by a negative feedback loop of circulating miR-146a and $-146 \mathrm{~b}$ in cardiovascular disease patients. PLoS One 12: e0181562, 2017.

16. Satoh M, Nasu T, Takahashi Y, Osaki T, Hitomi S, Morino Y and Nakamura M: Expression of miR-23a induces telomere shortening and is associated with poor clinical outcomes in patients with coronary artery disease. Clin Sci (Lond) 131: 2007-2017, 2017.

17. Inoue K: MicroRNA function in animal development. Tanpakushitsu Kakusan Koso 52: 197-204, 2007 (In Japanese).

18. Looney AM, Ahearne CE, Hallberg B, Boylan GB and Murray DM: Downstream mRNA target analysis in neonatal hypoxic-ischaemic encephalopathy identifies novel marker of severe injury: A proof of concept paper. Mol Neurobiol 54: 8420-8428, 2017.

19. Li S, Lee C, Song J, Lu C, Liu J, Cui Y, Liang H, Cao C, Zhang F and Chen H: Circulating microRNAs as potential biomarkers for coronary plaque rupture. Oncotarget 8: 48145-48156, 2017.

20. Wang Q, Ma J, Jiang Z, Wu F, Ping J and Ming L: Identification of microRNAs as diagnostic biomarkers for acute myocardial infarction in Asian populations: A systematic review and meta-analysis. Medicine (Baltimore) 96: e7173, 2017. 
21. Zhu ED, Li N, Li BS, Li W, Zhang WJ, Mao XH, Guo G, Zou QM and Xiao B: miR-30b, down-regulated in gastric cancer, promotes apoptosis and suppresses tumor growth by targeting plasminogen activator inhibitor-1. PloS One 9: e106049, 2014.

22. MacArthur Clark J: The 3Rs in research: A contemporary approach to replacement, reduction and refinement. Br J Nutr: 1-7, 2017.

23. Nwokeoji AO, Kilby PM, Portwood DE and Dickman MJ: RNASwift: A rapid, versatile RNA extraction method free from phenol and chloroform. Anal Biochem 512: 36-46, 2016.

24. Livak KJ and Schmittgen TD: Analysis of relative gene expression data using real-time quantitative PCR and the 2(-Delta Delta C(T)) method. Methods 25: 402-408, 2001

25. Zhang P, Wu X, Li G, He Q, Dai H, Ai C and Shi J: Tumor necrosis factor-alpha gene polymorphisms and susceptibility to ischemic heart disease: A systematic review and meta-analysis. Medicine (Baltimore) 96: e6569, 2017.

26. Xiao FY, Liu M, Chen BL, Cao S, Fan L, Liu ZQ, Zhou HH, Zhang W and Zhou G: Effects of four novel genetic polymorphisms on clopidogrel efficacy in Chinese acute coronary syndromes patients. Gene 623: 63-71, 2017.

27. Chistiakov DA, Grechko AV, Myasoedova VA, Melnichenko AA and Orekhov AN: Impact of the cardiovascular system-associated adipose tissue on atherosclerotic pathology. Atherosclerosis 263 : 361-368, 2017

28. Al Badarin F, Aljizeeri A, Almasoudi F and Al-Mallah MH: Assessment of myocardial blood flow and coronary flow reserve with positron emission tomography in ischemic heart disease: Current state and future directions. Heart Fail Rev 22: 441-453, 2017.

29. Tanabe N, Hiraoka E, Hoshino M, Deshpande GA, Sawada K, Norisue Y, Tsukuda J and Suzuki T: Progressive ischemic stroke due to thyroid storm-associated cerebral venous thrombosis. Am J Case Rep 18: 194-197, 2017.

30. Moreno JA, Gálvez MM, Cornudella R, Angós JA, Romero MS and Gutiérrez M: Fibrinolytic system in patients with myocardial infarction and other coronary disease risk factors. Sangre (Barc) 39: 111-116, 1994 (In Spanish).

31. Iida K, Tani S, Atsumi W, Yagi T, Kawauchi K, Matsumoto N and Hirayama A: Association of plasminogen activator inhibitor-1 and low-density lipoprotein heterogeneity as a risk factor of atherosclerotic cardiovascular disease with triglyceride metabolic disorder: A pilot cross-sectional study. Coron Artery Dis 28: 577-587, 2017.

32. Shimizu T, Uematsu M, Yoshizaki T, Obata JE, Nakamura T, Fujioka D, Watanabe K, Watanabe Y and Kugiyama K: Myocardial production of plasminogen activator inhibitor-1 is associated with coronary endothelial and ventricular dysfunction after acute myocardial infarction. J Atheroscler Thromb 23 557-566, 2016.

33. Denorme F, Wyseure T, Peeters M, Vandeputte N, Gils A Deckmyn H, Vanhoorelbeke K, Declerck PJ and De Meyer SF Inhibition of thrombin-activatable fibrinolysis inhibitor and plasminogen activator inhibitor-1 reduces ischemic brain damage in mice. Stroke 47: 2419-2422, 2016.

34. Seferovic MD and Gupta MB: Increased umbilical cord PAI-1 levels in placental insufficiency are associated with fetal hypoxia and angiogenesis. Dis Markers 2016: 7124186, 2016.

35. Ji Y, Meng QH and Wang ZG: Changes in the coagulation and fibrinolytic system of patients with subarachnoid hemorrhage. Neurol Med Chir (Tokyo) 54: 457-464, 2014.

36. Thögersen AM, Jansson JH, Boman K, Nilsson TK, Weinehall L, Huhtasaari $F$ and Hallmans G: High plasminogen activator inhibitor and tissue plasminogen activator levels in plasma precede a first acute myocardial infarction in both men and women: Evidence for the fibrinolytic system as an independent primary risk factor. Circulation 98: 2241-2247, 1998.
37. Hamsten A, de Faire U, Walldius G, Dahlén G, Szamosi A, Landou C, Blombäck M and Wiman B: Plasminogen activator inhibitor in plasma: Risk factor for recurrent myocardial infarction. Lancet 2: 3-9, 1987.

38. Chen R, Yan J, Liu P, Wang Z and Wang C: Plasminogen activator inhibitor links obesity and thrombotic cerebrovascular diseases: The roles of PAI-1 and obesity on stroke. Metab Brain Dis 32: 667-673, 2017.

39. Li JY, Li Y, Gong HY, Zhao XB and Li LZ: Protective effects of n-butanol extract of Potentilla anserina on acute myocardial ischemic injury in mice. Zhong Xi Yi Jie He Xue Bao 7: 48-52, 2009 (In Chinese).

40. Fu XC, Wang X, Zheng $\mathrm{H}$ and Ma LP: Protective effects of orientin on myocardial ischemia and hypoxia in animal models. Nan Fang Yi Ke Da Xue Xue Bao 27: 1173-1175, 2007 (In Chinese)

41. Maenpaa CJ, Shames BD, Van Why SK, Johnson CP and Nilakantan V: Oxidant-mediated apoptosis in proximal tubular epithelial cells following ATP depletion and recovery. Free Radic Biol Med 44: 518-526, 2008.

42. Kim JK, Pedram A, Razandi M and Levin ER: Estrogen prevents cardiomyocyte apoptosis through inhibition of reactive oxygen species and differential regulation of p38 kinase isoforms. J Biol Chem 281: 6760-6767, 2006.

43. Castedo E, Segovia J, Escudero C, Olmedilla B, Granado F, Blas C, Guardiola JM, Millán I, Pulpón LA and Ugartea J: Ischemia-reperfusion injury during experimental heart transplantation. Evaluation of trimetazidine's cytoprotective effect. Rev Esp Cardiol 58: 941-950, 2005 (In Spanish).

44. Bardooli F, McAlindon E, Littlejohns B, Suleiman MS Bucciarelli-Ducci C and Baumbach A: TCT-184 Early changes in circulating miRNA 133a are indicative of cardiac remodelling after 3 months in patients presenting with acute ST elevation myocardial infarction. J Am Coll Cardiol 68: B75-B76, 2016.

45. Wang Y, Ouyang M, Wang Q and Jian Z: MicroRNA-142-3p inhibits hypoxia/reoxygenationinduced apoptosis and fibrosis of cardiomyocytes by targeting high mobility group box 1 . Int J Mol Med 38: 1377-1386, 2016.

46. Singh GB, Raut SK, Khanna S, Kumar A, Sharma S, Prasad R and Khullar M: MicroRNA-200c modulates DUSP-1 expression in diabetes-induced cardiac hypertrophy. Mol Cell Biochem 424: 1-11, 2017.

47. Li X, Gao Y, Meng Z, Zhang C and Qi Q: Regulatory role of microRNA-30b and plasminogen activator inhibitor-1 in the pathogenesis of cognitive impairment. Exp Ther Med 11: 1993-1998, 2016.

48. Ma F, Li T, Zhang H and Wu G: MiR-30s family inhibit the proliferation and apoptosis in human coronary artery endothelial cells through targeting the 3'UTR region of ITGA4 and PLCG1. J Cardiovasc Pharmacol 68: 327-333, 2016.

49. Li F, Chen Q, Song X, Zhou L and Zhang J: MiR-30b Is involved in the homocysteine-induced apoptosis in human coronary artery endothelial cells by regulating the expression of caspase 3 . Int J Mol Sci 16: 17682-17695, 2015.

50. Wei C, Li L and Gupta S: NF-кB-mediated miR-30b regulation in cardiomyocytes cell death by targeting Bcl-2. Mol Cell Biochem 387: 135-141, 2014.

51. Song CL, Liu B, Wang JP, Zhang BL, Zhang JC, Zhao LY, Shi YF, Li YX, Wang G, Diao HY, et al: Anti-apoptotic effect of microRNA-30b in early phase of rat myocardial ischemia-reperfusion injury model. J Cell Biochem 116: 2610-2619, 2015.

52. Wang K, An T, Zhou LY, Liu CY, Zhang XJ, Feng C and Li PF: E2F1-regulated miR-30b suppresses Cyclophilin D and protects heart from ischemia/reperfusion injury and necrotic cell death. Cell Death Differ 22: 743-754, 2015. 